\section{Fronteras como herramienta metodológica para comprender territorios de interfaz en tierras secas}

\author{
Ana María Blanco Ávila \\ ORCID: https://orcid.org/0000-0002-7617-4766 \\ Instituto Regional de Planeamiento y Hábitat (IRPHa), \\ Universidad Nacional de San Juan/ CONICET, San Juan, \\ Argentina.
}

\section{Romina Giselle Sales \\ ORCID: https://orcid.org/0000-0003-1280-6637 Instituto Argentino de Investigaciones de las Zonas Áridas (IADIZA), Universidad Nacional de Cuyo/ Gobierno de Mendoza/ CONICET, Mendoza, Argentina. Instituto Regional de Planeamiento y Hábitat, Universidad Nacional de San Juan/ CONICET, San Juan, Argentina. Correo electrónico: rsales@mendoza-conicet.gob.ar}

\section{Resumen}

En América Latina, la expansión urbana sobre áreas rurales produce territorios de interfaz urbano-rural y acentúa problemáticas socioespaciales. Esto adquiere relevancia en tierras secas, como San Juan (Argentina), debido a las incidencias del soporte físico-biológico en la configuración territorial. En la provincia, esta dinámica se asocia, mayormente, con la construcción de viviendas de operatoria estatal. Aunque se encuentra en elaboración un marco normativo que busca restringir el consumo ilimitado de tierras agroproductivas debido al avance de la urbanización, las herramientas empleadas no logran abordar las particularidades de los territorios de interfaz. En este marco, seleccionamos un caso de estudio en el Área Metropolitana de San Juan, con el fin de elaborar una propuesta metodológica que presenta a las fronteras materiales y simbólicas como herramienta para el ordenamiento territorial. Aplicamos una estrategia metodológica mayormente cualitativa y utilizamos técnicas tales como la entrevista semiestructurada, observación en campo y análisis documental. Los resultados indican la relevancia de desarrollar indagaciones territoriales desde una perspectiva multidimensional y multiescalar que permita profundizar en las singularidades que presentan las áreas de interfaz urbano-rural. Al respecto, consideramos que la identificación de fronteras resulta útil para la definición de unidades de gestión territorial en tierras secas.

\section{Palabras clave}

Fronteras materiales, fronteras simbólicas, interfaz urbano-rural, ordenamiento territorial, territorio

\section{Boundaries as a methodological tool to understand interface territories in drylands}

\author{
Julieta Dalla Torre \\ ORCID: https://orcid.org/0000-0002-1355-0445 \\ Instituto Multidisciplinario de Estudios Sociales \\ Contemporáneos, Instituto de Estudios Históricos, \\ Económicos, Sociales e Internacionales (IDEHESI), \\ CONICET/ Universidad Nacional de Cuyo, Mendoza, \\ Argentina.
}

Financiamiento: Proyecto SIIP Tipo 1 Bienal 2019 Universidad Nacional de Cuyo.

\begin{abstract}
In Latin America, urban expansion in rural areas produces urban-rural interface territories and emphasizes socio-spatial problems. This is particularly relevant in drylands, such as San Juan (Argentina), due to the impact of the physical-biological structure on the territorial configuration. In the province, this dynamic is mostly associated with the construction of state-operated housing. Although a regulatory framework is being developed to restrict the unlimited consumption of agroproductive land due to the advance of urbanization, the tools used fail to approach the particularities of interface territories. In this context, we selected a case study in the Metropolitan Area of San Juan, in order to elaborate a methodological proposal that presents material and symbolic boundaries as a tool for land use planning. We applied a mostly qualitative methodological strategy and used techniques such as semistructured interview, field observation and documentary analysis. The results indicate the relevance of developing territorial research from a multidimensional and multiscale perspective that allows us to focus on the singularities of the urban-rural interface areas. In this sense, we consider that the identification of boundaries is useful for the definition of territorial management units in drylands
\end{abstract}

\section{Keywords}

Material boundaries, symbolic boundaries, territorial planning, territory, urban-rural interface 


\section{Introducción}

En América Latina, a partir de la década de 1990 y producto de la reestructuración económica de lógica neoliberal, se produjeron profundos cambios en los modos de pensar, planificar y gestionar las ciudades (De Mattos, 2002). Entre las transformaciones más destacadas, se evidencia la expansión urbana y los acelerados cambios de uso de suelo que han acentuado la desigual distribución de la riqueza y la fragmentación socioespacial (Janoschka, 2002; Jirón y Mansilla, 2014). En Argentina, la expansión de la urbanización sobre territorios productivos o de fragilidad ambiental no se correlaciona con las tasas anuales de crecimiento demográfico (Centro de Implementación de Políticas Públicas para la Equidad y el Crecimiento [CIPPEC], 2018), lo cual demuestra que dicho escenario se asocia con una planificación y gestión territorial insuficientes (De Mattos, 2002).

En la provincia de San Juan (Argentina), esta problemática no resulta ajena debido al continuo proceso de extensión del área urbana sobre tierras rurales promovido, principalmente, por las actuaciones de distintos agentes incluso algunos pertenecientes al Estado (CIPPEC, 2018). Ello contribuye a la configuración de territorios fragmentados en los que se acentúan, en algunos casos, dinámicas de fragmentación y segregación socioespacial (Dalla Torre, Sales, Esteves y Ghilardi, 2019). El avance de la urbanización se vincula, por un lado, con estrategias de desarrolladores inmobiliarios que buscan rentabilidad mediante la inversión privada en tierras susceptibles de ser urbanizadas mientras que, de fondo, se vislumbra una crisis de la producción agropecuaria que afecta la rentabilidad de los productores (Barsky, 2012; Malmod, 2011). Por otro lado, se identifican urbanizaciones estatales que, mediante las políticas habitacionales ejecutadas por el Instituto Provincial de la Vivienda (IPV) y Lote Hogar ${ }^{1}$, atienden el déficit habitacional de los grupos sociales más desfavorecidos. Paralelamente, el Programa de Crédito Argentino del Bicentenario (PRO.CRE.AR) desde el año 2012 también contribuye a la expansión urbana del Área
Metropolitana de San Juan (AMSJ) a través de acciones habitacionales destinadas a sectores socioeconómicos medios. Esta problemática adquiere mayor relevancia cuando la ciudad se extiende en territorios estructurados a partir de la disponibilidad o escasez del recurso hídrico, característica propia de tierras secas.

En este contexto, seleccionamos un sector de los municipios de Capital y Chimbas perteneciente al AMSJ como caso de estudio, para elaborar una propuesta metodológica desde el concepto de fronteras materiales y simbólicas como herramienta para el ordenamiento territorial (OT). Si bien la planificación de los territorios de tierras secas ha cobrado mayor relevancia en la agenda de gobierno en los últimos 20 años, el análisis de las fronteras materiales y simbólicas como instrumento posible para dar cuenta de los aspectos asociados al avance de la urbanización y a la conformación de territorios de interfaz urbanorural, aún no ha cobrado protagonismo en las políticas públicas de carácter territorial, específicamente, en las habitacionales y de OT. Particularmente en el caso analizado, ponemos en relevancia la producción de fronteras asociadas a la expansión urbana provocada por la cuantiosa construcción de viviendas por parte del IPV en territorios de interfaz urbano-rural.

En este contexto, nos preguntamos: ¿De qué manera podrían incorporarse las particularidades de los territorios de interfaz urbano-rural en las políticas públicas de carácter territorial? Por esto, el artículo se divide en tres partes, la primera presenta las características generales del caso de estudio a través de la noción de interfaz urbano-rural; seguidamente se profundiza en el análisis de las fronteras materiales y simbólicas allí construidas $y$, finalmente, se expone la propuesta de las fronteras como herramienta metodológica para la definición de unidades de gestión territorial. En esta línea, sostenemos que indagar en las fronteras - materiales y simbólicasconstruidas en tales territorios, resulta un instrumento de utilidad para la definición de unidades de gestión territorial basadas en aspectos multidimensionales y multiescalares que toman en cuenta elementos tales

1 Desde noviembre de 2019, el Régimen del Lote Hogar depende del IPV, según la Ley N 833-P. 
como, la superposición de las tramas urbano y rural, las barreras físicas naturales y construidas, la distancia a las fuentes laborales, el acceso al equipamiento escolar y sanitario, así como a las redes de servicios urbanos de infraestructura, la articulación entre instituciones y múltiples agentes territoriales, las redes comunitarias, los usos y apropiaciones de los espacios públicos y, las percepciones sobre barrios relocalizados, entre otros.

\section{Anclaje teórico}

En este trabajo, entendemos al territorio como una producción social que constituye una apropiación material y/o simbólica de un espacio por parte de agentes sociales a través de una dominación, control o delimitación que lo constituyan como tal (Dalla Torre et al., 2019; Haesbaert, 2013; Raffestin y Butler, 2012;). En esta línea, el territorio producido históricamente expresa sociabilidades, temporalidades y espacialidades específicas.

La interfaz urbano-rural es entendida como categoría resultante de la expansión urbana sobre territorios rurales. Allí interactúan los sistemas agrícolas, urbano y naturales en relación directa con los procesos socioeconómicos que caracterizan el crecimiento de la ciudad. La interfaz refiere a territorios que adquieren entidad propia en la medida en que obtienen propiedades de dos unidades diferentes en constante intercambio, es decir, se constituyen como unidades funcionales con características propias derivadas de esa interacción (Barsky, 2012; Dalla Torre et al., 2019). Esto explica la complejidad de analizar estos territorios en constante transformación. En América Latina, la construcción de territorios de interfaz urbano-rural, también denominados de borde urbano, periurbanos, etc. se explica a partir de la actuación de diversos agentes territoriales vinculados, mayormente, con la expansión resultante de la construcción de viviendas (Rodríguez, Vieyra, Méndez-Lemus, Hidalgo Dattwyler, Alvarado Peterson y Rodríguez, 2020). Entre estos se observan productores rurales de diversa escala, desarrolladores inmobiliarios, planificadores y gestores estatales de obra pública, cooperativistas, familias de diversos sectores socioeconómicos que despliegan sus estrategias reproductivas, entre otros. Tales agentes tienen diferente poder en la construcción del territorio expresado en la expansión del capital y sus consecuencias - tales como expulsión de productores rurales- asociados, desde el campo, a los agronegocios y desde la ciudad, al negocio inmobiliario (González Maraschio, 2018). Esto resulta aún más preocupante en tierras secas donde las limitaciones de acceso al recurso hídrico generan la desaparición de pequeñas explotaciones agrícolas ganaderas (Gudiño, 2010). Así, la búsqueda de tierras más asequibles económicamente por agentes de mayor poder redunda en la segregación de ciertos grupos sociales y la profundización de procesos de desigualdad (Di Virgilio, Guevara y Arqueros Mejica, 2014). En este contexto, resulta de suma importancia el papel que asume el Estado como agente regulador del mercado de suelo que dinamiza las problemáticas territoriales urbanas, rurales y de interacción urbanorural (Gudiño, 2010; Massiris Cabeza, 2002).

Al mismo tiempo, este artículo retoma el concepto de fronteras construidas a través de prácticas sociales en un momento y espacio determinado en las que se ponen en juego diferentes apropiaciones. Es decir, las fronteras están en continuo cambio debido a las dinámicas entre los agentes sociales que participan. La frontera es considerada una entidad espacial que mientras separa física, social, política y económicamente dos entidades, genera relaciones entre estas (Benedetti, 2020). Asimismo, la frontera como construcción sociohistórica condensa prácticas, relaciones y sentidos y articula dimensiones materiales y simbólicas. Remite tanto a una comunidad emplazada físicamente en un territorio, como a una comunidad simbólica (Dalla Torre et al., 2019). Al respecto, entendemos a la interfaz urbano-rural como una frontera que, al mismo tiempo, incluye otras de diferentes escalas. Las fronteras pueden ser materiales o físicas y manifestarse a distintas escalas de análisis permitiendo identificar articulaciones sociales en constante transformación, construidas en torno a elementos físicos tales como muros, avenidas, cursos hídricos, entre otras. En cuanto a las simbólicas, se relacionan con representaciones, imaginarios, significaciones y discursos que los agentes 
sociales construyen y transmiten respecto de sí mismos y de otros, refiriendo a lo propio y lo ajeno, lo barrial y el afuera, lo conocido y lo extraño (Dalla Torre et al., 2019).

Finalmente, resulta de interés el concepto de OT entendido como un proceso técnico, político y administrativo que tiende a configurar las prácticas de uso y ocupación, según las potencialidades y limitaciones del territorio, las aspiraciones de la población y los objetivos de desarrollo (Massiris Cabeza, 2002). Se considera una planificación y gestión que, con una visión integral y sistémica del territorio, puede atenuar los efectos de la urbanización acelerada posibilitando un desarrollo territorial más equitativo (Gudiño, 2010).

\section{Metodología}

En el marco del objetivo propuesto, el desarrollo metodológico implicó la adopción de una perspectiva mayormente cualitativa que combina técnicas documentales, conversacionales y observacionales. Se seleccionaron los departamentos de Capital y Chimbas por representar una de las áreas del AMSJ donde mayormente se ha concentrado la construcción de viviendas de operatoria estatal.

Respecto del análisis documental, se trabajó de manera crítica con fuentes de información secundaria en soporte escrito y visual, tales como los Censos Nacionales de Población, Hogares y Vivienda de la Argentina 2010 para caracterizar sociodemográficamente el área de estudio; documentos de políticas públicas provinciales y municipales referidas al período de estudio, tales como el Plan de Ordenamiento Territorial del Área Metropolitana de San Juan (PLAM-SJ), presentado en el año 2013 y revisado en 2015, comunicados de prensa gráfica y digital asociados a los anteproyectos y lineamientos de los planes territoriales municipales en desarrollo, documentos del IPV que permitieron identificar y caracterizar los barrios construidos, entre otros. También, se analizaron imágenes de alta resolución espacial de los años 2004 y 2020 en Google Earth, mediante la interpretación visual y su procesamiento en software libre QGIS, con la intención de identificar barrios de operatoria estatal durante ambos cortes temporales.

En cuanto a las técnicas conversacionales, durante el segundo semestre de 2020 se desarrollaron entrevistas semiestructuradas mediante plataforma virtual (debido a las restricciones impuestas por la pandemia de COVID-19) a agentes estatales, entre ellos funcionarios vinculados con la política habitacional provincial. Se priorizó la selección de personas con larga trayectoria que pudieran reconstruir las prácticas y fundamentos de los barrios construidos por el Estado durante los años objeto de estudio. Para recuperar sus discursos se diseñó una guía de entrevista en la que se incluyeron categorías vinculadas con los objetivos de la investigación, a partir de las cuales se buscó caracterizar la gestión estatal en el período analizado, así como las consideraciones respecto de la localización de barrios, provisión de servicios urbanos, procesos de adjudicación de las viviendas, relaciones público/privado/comunitario en la gestión territorial entre otros. Asimismo, se realizaron conversaciones informales con los y las vecinas que residen en el área de estudio, a fin de conocer sus experiencias cotidianas asociadas con el acceso a servicios y equipamientos urbanos, la adjudicación de una nueva vivienda y su incidencia en el acceso a fuentes laborales, la construcción de redes de proximidad intra e interbarriales, uso y apropiación de los espacios públicos, modalidades de movilidad y transporte empleado, entre otros.

Además, se realizaron observaciones directas durante los operativos de trabajo del equipo en el área, que permitieron complementar la información obtenida mediante trabajo en gabinete. Se registraron, a través de notas de campo, aspectos vinculados con la tipología de usos urbanos y rurales, indicios sobre cambios en los usos de la tierra, elementos que dividen espacios, redes de servicios urbanos de infraestructura, existencia de cursos de agua, ubicación de los diversos conjuntos residenciales, localización de fuentes de empleo, provisión del servicio de transporte público de pasajeros, ubicación y cantidad de establecimientos educativos y sanitarios, entre otros. 
El procesamiento y el análisis de la información de las observaciones en campo, así como de las entrevistas se basó en la Grounded Theory que consiste en la generación inductiva de núcleos temáticos o categorías surgidas sistemáticamente desde los datos. El proceso de análisis fue, mayormente, paralelo a la construcción de la información con la aplicación de la guía.

\section{Caso de estudio: territorio de interfaz urbano-rural en el Área Metropolitana de San Juan}

La provincia de San Juan está ubicada al oeste de la República Argentina, limitando al noreste con la provincia de La Rioja, al sureste con San Luis, al sur con Mendoza y al oeste con la República de Chile. La provincia posee $89.651 \mathrm{~km}^{2}$ donde prima, de oeste a este, un relieve montañoso intercalado por valles, llanuras y serranías. El clima es predominantemente templado y de extrema aridez, con limitados recursos hídricos superficiales y un promedio de precipitaciones de $100 \mathrm{~mm}$ anuales (Instituto Nacional de Tecnología Agropecuaria, 2020). Debido a las restricciones climáticas y la distribución de la red hidrográfica, las posibilidades para los asentamientos humanos se reducen al 3\% del territorio provincial, que se corresponden con la superficie de los oasis provinciales (Ministerio de Planificación e Infraestructura de San Juan [MPI-SJ], 2015). El valle de Tulum es el oasis de mayor extensión territorial y en el cual se ubica el Área Metropolitana de San Juan (AMSJ). Su conurbación está conformada por los municipios Capital, Chimbas, Rivadavia, Santa Lucía, Rawson y Pocito, ocupa una superficie de $127 \mathrm{~km}^{2}$ y posee 494.639 habitantes, lo que representa el 72,6\% de la población provincial (Instituto Nacional de Estadística y Censos [INDEC], 2010).

San Juan pertenece a las denominadas tierras secas las cuales se caracterizan por presentar una fragilidad ambiental que incide directamente en la configuración territorial (Rubio, Rubio \& Abraham, 2018). Además, la elevada dispersión que posee la expansión urbana indica la falta de racionalidad en los modos de ocupación del territorio (Malmod, 2011). La urbanización sobre las áreas productivas adquiere una significación particular en la medida en que profundiza el avance de la desertificación en un territorio ambientalmente frágil (Rojas, Rubio, Rizzo, Bernabeu, Akil y Martín, 2020; Taber y Nozica, 2011). Esta lógica de crecimiento urbano es insuficientemente regulada lo cual, además de encarecer la provisión de servicios urbanos, presiona sobre la red de abastecimiento hídrico, avanza sobre el suelo productivo y configura un territorio fragmentado, particularmente hacia los bordes del aglomerado. Asimismo, el actual patrón de ocupación territorial demanda grandes cantidades de suelo y distribuye, en general, en sentido norte-sur, la localización de los grupos sociales de medios y bajos ingresos y, en este-oeste, a aquellos de altos ingresos (MPI-SJ, 2015). Paralelamente, se evidencia que la tasa de expansión del AMSJ quintuplica la tasa de crecimiento poblacional (Gobierno de la Nación Argentina y Centro de Investigaciones de Políticas Urbanas y de Vivienda, 2017). Considerando que la ciudad se desarrolla sobre un oasis construido en un ambiente árido, tales cifras señalan una utilización insostenible de los recursos naturales y una baja densidad en el crecimiento urbano.

Para dar respuesta al avance urbano sobre territorios rurales, la provincia se encuentra elaborando un marco normativo de OT que comenzó con el Plan de Ordenamiento Territorial del Área Metropolitana de San Juan (PLAMSJ) realizado en el año 2013 y revisado en 2015. En el mismo año se creó el Consejo para la Planificación Estratégica de San Juan (CoPESJ) con el objetivo de orientar la definición de políticas públicas y decisiones vinculadas con el OT. En esta línea, el CoPESJ se encargó de guiar el Plan Estratégico San Juan 2030 (PESJ 2030) considerando los Objetivos Mundiales de Desarrollo Sostenible. Este plan propone avanzar sobre ejes centrales entre los que destacan la ocupación y uso del territorio, desarrollo urbano y rural, hábitat, ambiente y recursos naturales. Sin embargo, como también ocurre en otros territorios latinoamericanos, los avances sobre el estudio diagnóstico de los territorios de interfaz urbano-rural y el desarrollo de lineamientos concretos para su gestión aún resultan un desafío pendiente. En este marco, el gobierno provincial ha convocado a los municipios a elaborar sus planes estratégicos municipales de OT y Desarrollo Local. Para ello, el municipio de Capital se 
Figura 1

El caso de estudio al interior del AMSJ, San Juan, Argentina

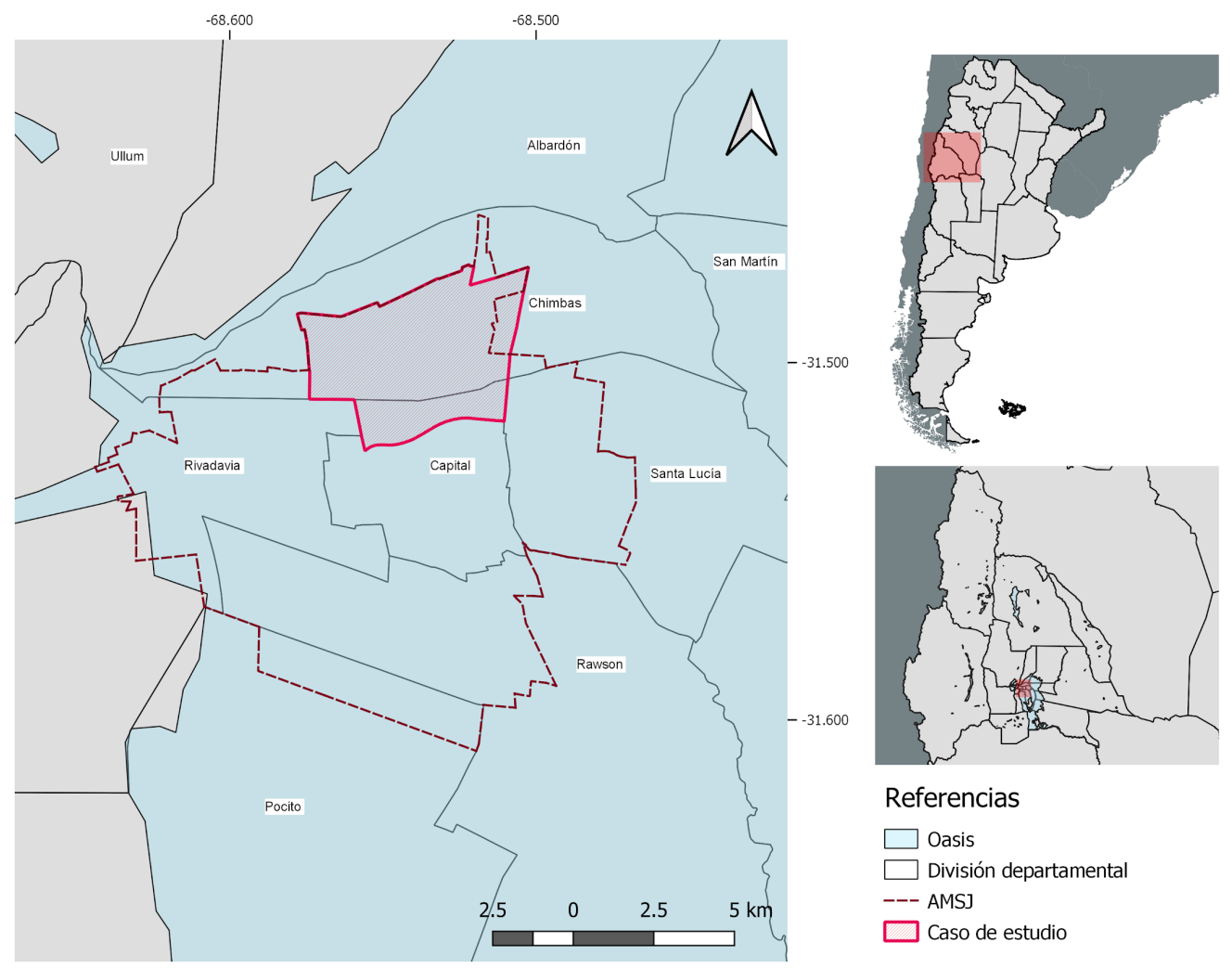

Nota. Elaboración propia sobre la base de datos del Instituto Geográfico Nacional de la República Argentina y Atlas socioeconómico de la Provincia de San Juan (Universidad Nacional de San Juan, 2012).

encuentra actualmente trabajando en los lineamientos de su política territorial, mientras que, el municipio de Chimbas ha presentado recientemente las premisas del “Plan Chimbas 2030" donde especifica las estrategias para la planificación territorial y la redefinición del perfil productivo municipal. No obstante, se observa en los avances presentados que el abordaje de los territorios de interfaz en ambos municipios queda relegado frente a las problemáticas urbanas o rurales.

Al interior del AMSJ, seleccionamos como caso de estudio una porción territorial conformada por los municipios de Capital y Chimbas, la cual se encuentra delimitada a partir de ejes viales principales (Figura 1). Este recorte se justifica teniendo en cuenta que el municipio Capital se caracteriza por ser una zona urbana en la cual se concentra el equipamiento urbano, la población y las actividades socioculturales y económicas de la provincia, generando una fuerte dependencia funcional de los municipios colindantes. Por el contrario, el departamento Chimbas se presenta como un territorio históricamente configurado como territorio rural en el que se agrupaban actividades agroproductivas, pero que, en las últimas dos décadas, ha sido fuertemente transformado por el avance de la urbanización. De esta manera, se configuran entre ambos municipios lo que denominamos territorio de interfaz urbano-rural, promovido, en el caso de estudio, por la producción estatal de hábitat residencial, hecho que se replica en diversos territorios de tierras secas.

El municipio Chimbas presenta un incremento de 35 mil habitantes que explica un tercio del crecimiento poblacional registrado del AMSJ y significa una variación de crecimiento poblacional intercensal 1991-2010 del 66,96\% (INDEC, 2010; MPI-SJ, 2015). Por el contrario, Capital es el único municipio que ha decrecido desde 1991, contabilizando más de 10 mil habitantes en comparación con 2010, lo cual se traduce en una variación relativa del 8,62\% (MPI-SJ, 2015). Este crecimiento poblacional se observa en la expansión urbana residencial del AMSJ, aunque no lo explica de forma exclusiva, ya que esta se vincula, en gran parte, con la estructuración del 
mercado de tierras y la asignación de usos del suelo. En este contexto, la rentabilidad de las actividades define las transformaciones del territorio siendo, en general, la renta urbana significativamente más elevada que la agraria (González Maraschio, 2018). Respecto de los municipios que integran el caso de estudio, se observa que Capital es el que mayor proporción de viviendas deshabitadas presenta, con casi un quinto del total (más del 40\%), mientras que Chimbas posee la menor incidencia del AMSJ con casi el 10\% (MPI-SJ, 2015). Respecto del suelo urbano en desuso, expresado en cantidad de parcelas urbanas no edificadas, los municipios presentan cifras semejantes donde Capital cuenta con el 13,5\% del total metropolitano de terrenos baldíos y Chimbas con el 12,6\% (MPI-SJ, 2015). Esto evidencia la lógica de urbanización que ha caracterizado al AMSJ en las últimas décadas e invita a reflexionar acerca de las potencialidades y restricciones que existen en torno a un crecimiento disperso y de baja densidad respecto de otro compacto.

Las características que indican la acelerada expansión urbana son observables, también, en la conectividad de los territorios de interfaz con el AMSJ. Al respecto es posible identificar una escasa cobertura del servicio de transporte público reflejado en los pocos recorridos intersectoriales existentes lo que, a su vez, determina niveles de accesibilidad diferenciales a las redes metropolitanas entre los diversos grupos sociales (MPI-SJ, 2015). En lo que respecta a la provisión de equipamiento sanitario y educacional, el sector muestra una oferta de servicios suficientes, sin embargo, teniendo en cuenta las tendencias de urbanización (MPI-SJ, 2015) y lo que podrían implicar en el corto plazo, la necesidad de mayor equipamiento de salud y educación para cubrir las demandas de la comunidad es evidente. Asimismo, las entrevistas realizadas indican que, en algunos casos, los y las vecinas se trasladan al AMSJ para acceder a centros de salud y educativos. Acerca de los servicios urbanos de infraestructura, es posible evidenciar una cobertura desigual de las redes de agua potable, gas, electricidad y desagüe cloacal (MPI-SJ, 2015).
En cuanto a los agentes partícipes de la expansión urbana, resulta posible identificar que la producción de tejido de uso residencial que impulsa los cambios de uso de suelo se encuentra mayormente asociada a la construcción de viviendas de operatoria estatal (Ministerio de Obras Públicas de la Nación Argentina, 2011). Durante décadas la Argentina ha presentado un déficit habitacional estructural (Rodulfo y Boselli, 2014), acentuado en Buenos Aires y en el norte del país. Por su parte, regiones como Cuyo, a la que pertenece San Juan, presentan valores menos críticos. Hacia el año 2004, el Estado nacional ha desarrollado una Política Federal de Vivienda mediante programas federales que se suman al Fondo Nacional de la Vivienda ${ }^{2}$ (FONAVI) para generar la reactivación de la obra pública nacional en respuesta al déficit habitacional existente. En este contexto, los IPV son los responsables en instrumentar tales programas interviniendo incluso, en algunos casos, directamente en los municipios y/o organizaciones de la sociedad civil.

En este marco, identificamos como algunas acciones de la política habitacional que dinamizan la expansión urbana, la construcción de viviendas mediante la operatoria de demanda libre. Al interior de esta modalidad, es posible encontrar diversas opciones tendientes a atender el déficit habitacional. En algunos casos, las familias participan de un sorteo a fin de acceder a terrenos urbanizados para una posterior asistencia financiera individual que posibilite la construcción de su vivienda unifamiliar. Esta iniciativa está dirigida al sector de la población que tiene capacidad de ahorro y que puede pagar una cuota desde el inicio del proyecto, ya que como garantía de pago se confeccionan hipotecas a favor de IPV. Por otro lado, es posible acceder a esta operatoria a través de gremios, mutuales o asociaciones civiles que disponen de un terreno y solicitan asistencia financiera al IPV para la construcción del conjunto habitacional. De igual manera, aquellas familias que no formen parte de los grupos anteriores y cumplan con los requisitos definidos por IPV podrán postularse para participar del sorteo a fin de determinar, luego de una evaluación, aquellas

2 Creado en 1972 e instrumentado en 1977 como un sistema habitacional de provisión pública centralizado con planificación y financiamiento del gobierno nacional y ejecución de los IPV. 
Figura 2

Barrios de operatoria estatal construidos por IPV en el caso de estudio durante el periodo 2004-2020 y previamente
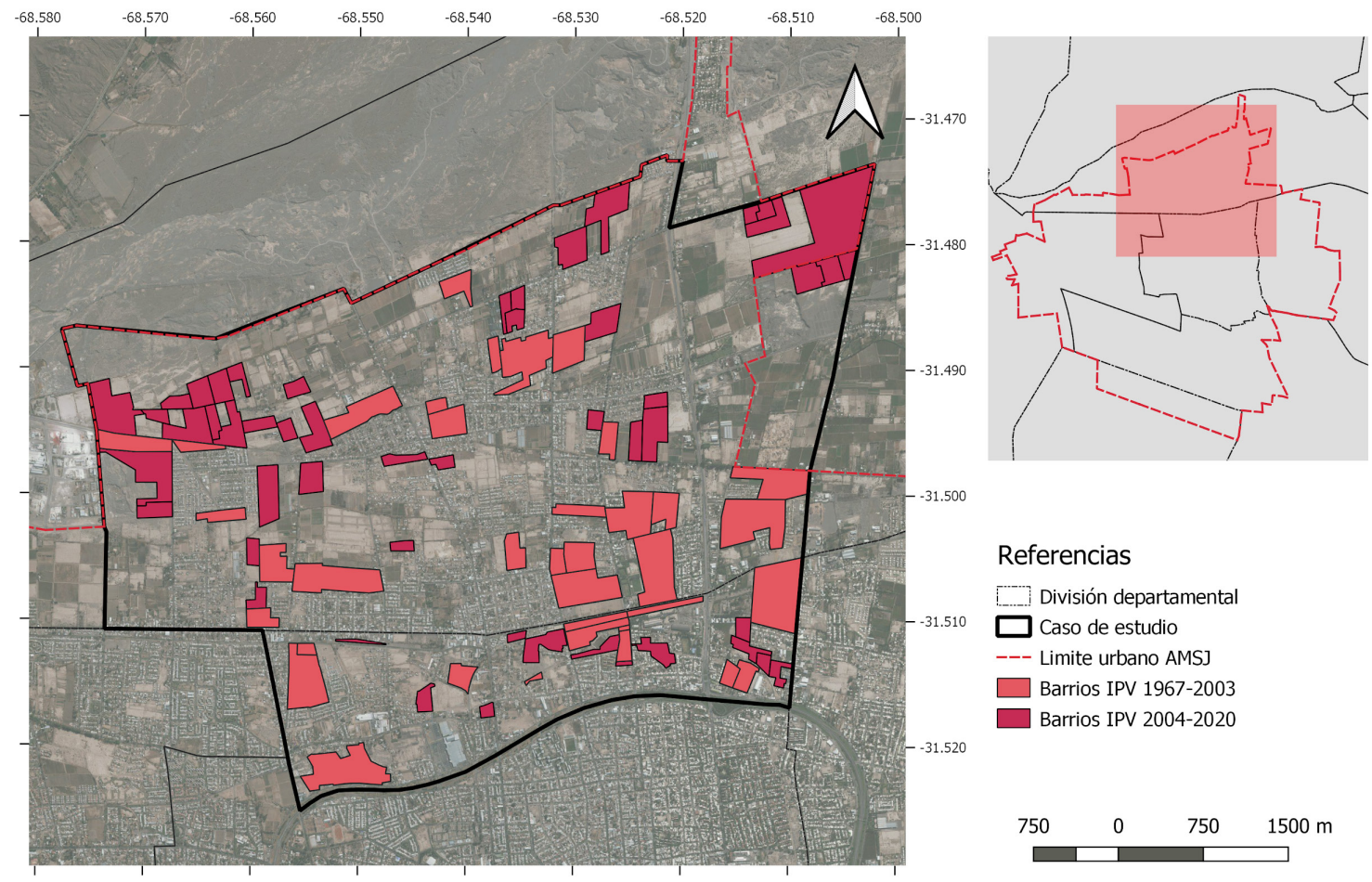

Referencias

$\square$ División departamental

$\square$ Caso de estudio

--- Limite urbano AMSJ

$\square$ Barrios IPV 1967-2003

Barrios IPV 2004-2020

750

0

$750 \quad 1500 \mathrm{~m}$

Nota. Elaboración propia en base a datos del Instituto Geográfico Nacional de la República Argentina y Atlas socioeconómico de la Provincia de San Juan (Universidad Nacional de San Juan, 2012), IPV y Google Earth (2015).

adjudicatarias de las viviendas. Los terrenos involucrados pertenecen al Banco de Tierras de la provincia. Luego de que IPV llama a licitación, se urbaniza y se proyecta el conjunto barrial.

Paralelamente, resalta el Plan Provincial Vivienda DignaTecho Seguro a través del cual el Estado provincial mediante la Ley $\mathrm{N}^{\circ} 7491 / 2004$ busca solucionar la precariedad habitacional existente en el AMSJ. El plan propone la promoción de acciones que, en el corto plazo, permitan la satisfacción del derecho humano básico de acceso a la vivienda, ejecutando la construcción y adjudicación de unidades habitacionales en condiciones de seguridad física, sanitaria y jurídica, con criterios de equidad, solidaridad, igualdad de oportunidades y justicia social (Ley $\left.\mathrm{N}^{\circ} 7491,2004\right)$. Para alcanzar dicho propósito, la iniciativa incluyó diversos programas y proyectos, entre los que interesa destacar, el Proyecto de Erradicación y Relocalización de Villas. Desarrollada durante el período 2004-2015, se orientó a la erradicación de 89 asentamientos en los que vivían alrededor de 5.570 familias y 27.851 personas en condiciones de pobreza e irregularidad jurídica y, su posterior relocalización en diversos barrios construidos por el IPV en el AMSJ. En este marco, el municipio de Chimbas destaca como uno de los que más familias relocalizadas albergó, aproximadamente un total de 1.213 en 15 conjuntos residenciales construidos a tal fin. Asimismo, en Chimbas fueron erradicados 10 asentamientos de 786 familias y relocalizadas a otros municipios. De manera opuesta, en el municipio de la Capital se registra la mayor cantidad de asentamientos erradicados, un total de 23 en donde habitaban 1.522 familias y, en el que menos conjuntos residenciales para familias relocalizadas se construyeron, solo cuatro barrios destinados a 311 familias (Scognamillo, Albarracín y Romero, 2016).

Al interior del AMSJ, los datos dan cuenta de la incidencia de las mencionadas políticas públicas en las transformaciones territoriales del aglomerado urbano. A través del relevamiento realizado y el análisis de la ubicación de los conjuntos barriales se observa la existencia de al menos 51 barrios construidos por operatoria estatal del IPV entre el 2004-2020 que indican una marcada expansión urbana y la construcción de nuevas fronteras (Figura 2). 
La espacialización de las diversas localizaciones de los barrios construidos por el IPV en el caso de estudio, da cuenta de una extensión urbana hacia territorios rurales localizados en los bordes del AMSJ. Esta dinámica, que caracteriza los patrones de urbanización difusos y de baja densidad, se observa acentuada durante el período de análisis. Específicamente, el $75 \%$ de los barrios (39 de 51) se localizan al interior del departamento Chimbas, de los cuales la mayoría se ubica en los extremos noreste y noroeste avanzando sobre territorios actualmente rurales e industriales/rurales. Por su parte, en el departamento Capital se localiza el $25 \%$ de los barrios restantes (12 de 51) emplazados en intersticios urbanos vacantes que intentan consolidar el área urbana. Al mismo tiempo, se evidencia una menor presencia de barrios construidos por IPV hacia el sur del departamento Chimbas y en el departamento Capital durante el período 2004-2020. No obstante, la existencia de conjuntos residenciales ejecutados en años anteriores (1967-2003) da cuenta de una expansión hacia los bordes del AMSJ desde la década de 1960. En este sentido, se observa un asimétrico desarrollo de conjuntos barriales al interior del caso de estudio que colabora con la producción y reproducción de fronteras materiales y simbólicas.

\section{Fronteras materiales y simbólicas asociadas a la expansión urbana en el caso de estudio}

Las intervenciones estatales explicitadas previamente forman parte de un conjunto de acciones que han promovido los procesos de expansión urbana evidenciados en el caso de estudio durante 2004-2020. En este apartado interesa analizar los procesos de construcción de fronteras materiales y simbólicas, así como la identificación de estas en el caso de estudio, a fin de aproximarnos a la caracterización de la interfaz urbano-rural. Para esto, prestamos especial atención a la generación de encuentros y desencuentros que producen las fronteras en un determinado territorio caracterizado por la relocalización de vecinos/as, asociadas a las limitadas posibilidades frente a la elección de las zonas a donde vivir. En términos generales, sostenemos que resultan útiles las técnicas observacionales que posibilitan detectar elementos visibles y, por ende, dar cuenta de la existencia de fronteras materiales. Asimismo, las técnicas conversacionales permiten recuperar las percepciones sociales en torno a la construcción de fronteras materiales y simbólicas. Respecto de la detección de ambos tipos de fronteras, la revisión y el análisis documental colaboran a tal fin.

\section{Fronteras materiales construidas a través de:}

\section{a. Superposición de las tramas urbano y rural}

En el caso se vislumbra la coexistencia, mayormente, de usos de la tierra residenciales y vacantes o baldíos, agroproductivos y, minoritariamente, zonas naturales (MPI-SJ, 2015). Según los datos obtenidos en la observación en campo y el análisis de imágenes satelitales, los usos residenciales presentan cierto grado de consolidación hacia el sur del área y se distribuyen, hacia el resto del sector, de forma aislada y a través de las principales vías de circulación vial. Asimismo, las áreas vacantes o baldías, colindando con la costanera del río San Juan, adquieren mayor protagonismo hacia el norte del caso y señalan los vestigios de usos agroproductivos pasados, casi ya inexistentes. En esta línea, la heterogeneidad en la distribución y preponderancia de usos de la tierra colabora con los procesos de fragmentación territorial.

\section{b. Barreras físicas naturales y construidas}

En el caso de estudio se observan elementos tales como extensos muros linderos, red de canales de riego, red de circulación vial, redes de tendido eléctrico de media y alta tensión, el corredor de la costanera del río San Juan y el propio río San Juan, entre otros. Estas barreras físicas producen, en algunos casos, espacios residuales en su entorno inmediato que fragmentan el tejido físico y social (MPI-SJ, 2015). Tal es el caso de uno de los barrios populares del sector que, según indican los agentes estatales entrevistados, debió ser relocalizado debido a su ubicación cercana al tendido eléctrico de alta tensión que ponía en riesgo la vida de los y las vecinas. Al realizarse el traslado hacia otro sector del AMSJ, se perdieron lazos de proximidad generados 
con otros/as vecinas quedando el espacio baldío. De forma similar, según lo observado en campo, sucede con las áreas cercanas a las redes de canales de riego y acequias de distribución que atraviesan el sector de oeste a este generando no solo espacios intersticiales entre las áreas barriales sino fraccionando el tejido al interior de conjuntos residenciales.

\section{c. Distancia a fuentes laborales}

Resulta posible identificar barrios de operatoria estatal localizados principalmente hacia el este y oeste del caso de estudio, por fuera de la mancha urbana consolidada. Al respecto, las entrevistas realizadas a agentes estatales indican que, en numerosas ocasiones, la ubicación de los conjuntos residenciales condiciona el acceso a diversas fuentes de empleo debido, principalmente, a las distancias que la población debe recorrer. En el caso de estudio, esto se observa en las relocalizaciones de hogares debido a su exposición a riesgos socioambientales en las viviendas de origen. Asimismo, sucede con las familias partícipes de los sorteos de viviendas que realiza el IPV, en el marco de los programas de operatoria de demanda libre, donde la distancia al mercado laboral desde la vivienda adjudicada es mayor. Paralelamente, la observación en campo y las conversaciones informales con los y las vecinas, permiten evidenciar en el caso de estudio, una reducida oferta del servicio de transporte público, observable no solo en la escasa conectividad que presenta sino además, en las limitaciones relacionadas con la frecuencia de recorridos ofrecidos (MPI-SJ, 2015). Esto se traduce en mayor tiempo requerido para trasladarse, lo que acentúa la vulnerabilidad de la población para acceder al mercado laboral y señala la separación entre las zonas de trabajo y residencia.

\section{d. Acceso a equipamiento escolar y sanitario}

Se observa que los centros educativos y sanitarios se encuentran, mayormente, concentrados hacia el sur y el centro del caso, coincidente con la trama urbana más consolidada (MPI-SJ, 2015). Por el contrario, el resto del área de estudio manifiesta una reducida oferta de este equipamiento. La observación en campo, además, da cuenta de la reducida cobertura del servicio de transporte público de pasajeros en las zonas más intersticiales del caso de estudio lo que genera que parte de la población se vea restringida para acceder al equipamiento escolar y sanitario. Según indican las entrevistas realizadas a agentes estatales, la proyección y ejecución de conjuntos residenciales en el caso de estudio se centra en las necesidades de infraestructura y equipamiento de la futura población, sin considerar las demandas de la población existente. Lo expuesto incide, también, en que la población, tal como refieren los y las vecinas en conversaciones informales, deba trasladarse hacia otros sectores al interior del área y, al no poder hacerlo por las limitaciones mencionadas respecto del servicio de transporte público, se dirija hacia el AMSJ. Esto evidencia los procesos de exclusión social por los que transitan parte de las comunidades que residen en el sector.

\section{e. Acceso a las redes de servicios urbanos de infraestructura}

En el caso de estudio, la observación de campo, así como los datos provistos por los agentes estatales en las entrevistas realizadas, indican que las viviendas adjudicadas en el sector están provistas de red de gas, agua, electricidad y cloacal, aunque sin conexión domiciliaria asegurada. Según tales entrevistas, la conexión a la red pública conlleva una inversión económica que muchos hogares se ven imposibilitados de realizar. Esto explica, en parte, la desigual cobertura de este servicio en el sector (MPI-SJ, 2015). Si bien, el tendido eléctrico y gasífero, así como la red de agua potable tienen gran alcance en determinadas zonas, las conversaciones informales con vecinos y vecinas indican que, en momentos de mayor consumo, los servicios funcionan de manera deficiente. Acerca de la red cloacal, se muestra en el sector una cobertura mínima, ya que cuentan con este servicio únicamente las viviendas localizadas hacia el sur del área. Lo expuesto, acentúa la insatisfacción de parte de las necesidades básicas de la población y, en consecuencia, indica las condiciones de precariedad habitacional de la población (MPI-SJ, 2015). 


\section{Fronteras simbólicas construidas a través de:}

\section{a. Articulación institucional y multiactoral}

Las entrevistas realizadas a agentes estatales señalan que las intervenciones ejecutadas en el sector durante los últimos años han sido el resultado del trabajo conjunto entre las dependencias gubernamentales encargadas de la proyección de los conjuntos barriales. No obstante, también advierten que aún queda por desarrollar instancias de colaboración con otras dependencias, principalmente, aquellas vinculadas con las prácticas de planificación y gestión territorial. Asimismo, resulta oportuno pensar en la creación de redes de articulación no solo gubernamentales sino también multiactorales, es decir, con agentes del sector técnico, científico-académico, privado y comunitario. Al respecto, se considera que el fortalecimiento de estas iniciativas de gestión asociada entre diferentes instituciones gubernamentales, así como entre diferentes agentes, colabora con la consolidación de procesos participativos que posibilitan la construcción de territorios más integrados.

\section{b. Posibilidades de uso y apropiación de los espacios públicos}

En las observaciones en campo se identifican espacios públicos tales como, plazas barriales, parque municipal, pasajes de circulación peatonal, entre otros. Aunque, en términos generales, son considerados como espacios de encuentro por los y las vecinas, según indican las conversaciones informales realizadas; también, se evidencia que, su ubicación y diseño, condicionan las posibilidades de uso. Lo anterior está asociado a una estratificación social definida por determinadas características, principalmente, adscriptivas (riqueza, pertenencia a un pueblo indígena, género, entre otras) que define quiénes pueden o no apropiarse de un espacio público. En el caso de estudio se puede observar lo expuesto en los grupos sociales que hacen uso del parque municipal (público y accesible por todos) y aquellos parquizados que preceden los accesos a los barrios privados (público, pero accesible solo para quienes allí habitan). Asimismo, el tipo de prácticas cotidianas habilitadas, implícitamente, a desarrollar en un espacio público u otro difieren. Esta heterogeneidad en la expresión de la vida cotidiana de los grupos sociales manifiesta en los espacios públicos, denota las desigualdades sociales producidas.

\section{c. Construcción de redes comunitarias}

En el caso de estudio se vislumbran redes locales de proximidad construidas por parte de los y las vecinas en torno al despliegue de estrategias de reproducción social. Algunas de estas redes, según indica la observación en campo, explican la existencia de alrededor de 14 organizaciones de base comunitaria consolidadas, tales como uniones vecinales, merenderos, bibliotecas populares, entre otros. Asimismo, las conversaciones informales con vecinos y vecinas permiten estimar que estas redes contribuyen a la integración vecinal y promueven la generación de otras. Por su parte, las entrevistas con agentes estatales refieren a que la institucionalización de estas redes comunitarias posibilita la mediación entre las autoridades gubernamentales y los y las vecinas, en torno a la búsqueda de satisfacer las necesidades de la comunidad. Se considera que la generación de espacios con representatividad vecinal que promueva la participación y colaboración posibilita la gestión de proyectos vecinales y colabora con la consolidación del tejido social lo que, a su vez, permite reducir los procesos de segregación socioespacial.

\section{d. Percepciones sobre barrios relocalizados}

En el caso de estudio, los procesos de erradicación y relocalización barrial han llevado a pérdidas de corresidencia familiar y al deterioro de vínculos vecinales y comunitarios preexistentes, según señalan las conversaciones informales con vecinos y vecinas. Asimismo, las entrevistas realizadas a agentes estatales indican que la reubicación de los grupos familiares provoca nuevos conflictos vecinales y, en muchos casos, acrecienta la discriminación hacia los nuevos habitantes que, considerados extraños/as y una posible amenaza, son estigmatizados. Esto se acentúa en áreas al interior del sector donde coexisten barrios de operatoria estatal y barrios cerrados de operatoria privada, donde la polarización social en torno al hábitat residencial es fuertemente evidenciada entre los diversos grupos sociales. 


\section{Propuesta metodológica: el análisis de las fronteras materiales y simbólicas de territorios de interfaz urbano-rural como herramienta para el ordenamiento territorial}

Teniendo en cuenta los datos empíricos del caso de estudio sobre el cual identificamos fronteras, en este apartado desarrollamos una propuesta de tipología de fronteras materiales y simbólicas como herramientas útiles para la elaboración de unidades de gestión territorial. $\mathrm{Si}$ bien en Latinoamérica el OT concibe al territorio como un sistema complejo, aún el foco se encuentra mayormente concentrado en los territorios urbanos o rurales, por separado. En este caso, nos concentramos en los territorios de interfaz urbano-rural para dar cuenta de sus singularidades.

La propuesta metodológica está conformada por tres ejes principales: indicadores de fronteras, técnicas e instrumentos de recolección de datos y posibles agentes clave para la recolección de datos. Asimismo, advirtiendo la complejidad que implica dar cuenta del carácter multiescalar y multidimensional del OT, se intenta ampliar la mirada acerca de los territorios de interfaz e indagar, al interior de estos, en las heterogeneidades que presentan y entendemos necesario atender.

Teniendo en cuenta que la expansión urbana acelerada sobre territorios rurales es una característica actual de los procesos de urbanización latinoamericanos, consideramos que esta propuesta es posible de ser replicada, en otros territorios de tierras secas. La propuesta metodológica consiste en identificar cinco fronteras materiales y cuatro fronteras simbólicas. Si bien las fronteras se presentan ordenadas desde el mayor grado de abstracción al menor, se sugiere realizar un plan de acción para las salidas a campo que permita tomar datos de forma estratégica, no necesariamente de forma lineal. Al interior de cada frontera, tanto material como simbólica, se desarrollan algunos indicadores que se constituyen en los elementos empíricos que consideramos relevantes para la identificación de tales fronteras. Por otra parte, se exponen las técnicas e instrumentos necesarios para la recolección de datos y el abordaje de los indicadores. Cabe aclarar que en la presente propuesta ampliamos las técnicas utilizadas en el análisis del caso de estudio, ya que consideramos que permitirán enriquecer el abordaje de territorios de interfaz en tierras secas. Asimismo, se reconocen posibles agentes clave pertenecientes a los sectores privados, gubernamentales, científicoacadémicos y comunitarios, entre otros, que permitan el acceso a los datos necesarios de recolectar (Tablas 1 y 2). Paralelamente, se identifican, en términos generales, tres etapas clave para la recolección de datos: trabajo en gabinete, salidas a campo y ajuste de datos en gabinete. Al mismo tiempo, advertimos la necesidad de contar con técnicos que posean con conocimientos sobre análisis de imágenes satelitales y de cartografías, elaboración de guía para entrevistas y ejes estructuradores para conversaciones informales, realización de entrevistas, relevamiento técnico, análisis de contenido documental y estadístico, entre otros. Paralelamente, resulta estratégica la articulación con diferentes organismos estatales para el acceso a datos de interés, tales como servicios de transporte público, de infraestructura urbana, entre otros.

\section{Reflexiones finales}

En el presente trabajo reflexionamos acerca de la conformación de territorios de interfaz frente a la acelerada expansión urbana sobre territorios rurales, particularmente en tierras secas. La relevancia que adquiere la urbanización en estas tierras está asociada, principalmente, al progresivo avance de procesos de desertificación provocados por la disminución o eliminación de suelos agroproductivos, lo cual afecta la sustentabilidad ecológica del territorio y, consecuentemente, la calidad de vida de la población. Al mismo tiempo, advertimos en los últimos años profundos avances en términos de planificación territorial expresados en las políticas de OT, tanto a nivel nacional como provincial y municipal. Sin embargo, identificamos que aún queda pendiente profundizar en el estudio de las particularidades que adquieren los territorios de interfaz en tierras secas, así como en la elaboración de unidades de gestión territorial que incorporen tales territorios. En este sentido, seleccionamos una zona del AMSJ como caso de estudio caracterizado, principalmente, por el avance 
Tabla 1

Identificación de fronteras materiales. Reflexiones desde el caso de estudio

\begin{tabular}{|c|c|c|c|}
\hline Fronteras materiales & Indicadores y observables & $\begin{array}{l}\text { Técnicas e instrumentos de } \\
\text { recolección de datos }\end{array}$ & $\begin{array}{l}\text { Agentes clave para la recolección } \\
\text { de datos }\end{array}$ \\
\hline $\begin{array}{l}\text { Superposición de las tramas } \\
\text { urbano y rural }\end{array}$ & $\begin{array}{l}\text { - Tipología de usos urbanos y usos } \\
\text { rurales. } \\
\text { o Cambios en los usos de la tierra. } \\
\text { o Trayectorias y movilidades de los } \\
\text { grupos sociales. }\end{array}$ & \multirow{2}{*}{$\begin{array}{l}\text { o Observación no participante. } \\
\text { o Relevamiento técnico. } \\
\text { o Análisis de imágenes satelitales, } \\
\text { cartografía histórica, documentos } \\
\text { científico-académicos e informes y } \\
\text { planos técnicos. } \\
\text { o Fotografía propia. } \\
\text { o Encuestas. } \\
\text { o Entrevistas semiestructuradas. }\end{array}$} & $\begin{array}{l}\text { - Agentes estatales. } \\
\text { o Desarrolladores inmobiliarios. } \\
\text { o Productores rurales. } \\
\text { o Técnicos y técnicas. } \\
\text { o Investigadores e investigadoras } \\
\text { locales. }\end{array}$ \\
\hline $\begin{array}{l}\text { Barreras físicas naturales y } \\
\text { construidas }\end{array}$ & $\begin{array}{l}\text { o Amurallamientos. } \\
\text { o Existencia de redes de riego, } \\
\text { viales, eléctricas. } \\
\text { o Costaneras. } \\
\text { o Cursos de agua. } \\
\text { o Distancia a los conjuntos } \\
\text { residenciales. }\end{array}$ & & $\begin{array}{l}\text { O Agentes estatales. } \\
\text { o Empresas prestadoras de } \\
\text { servicios infraestructurales. } \\
\text { o Técnicos y técnicas. }\end{array}$ \\
\hline Distancia a fuentes laborales & $\begin{array}{l}\text { o Ubicación de barrios de } \\
\text { operatoria estatal. } \\
\text { o Localización de fuentes de } \\
\text { empleo. } \\
\text { o Disponibilidad y alcance del } \\
\text { servicio de transporte público. } \\
\text { o Modalidades de movilidad y } \\
\text { transporte empleadas. } \\
\text { o Tiempos y costos de traslado. }\end{array}$ & \multirow{3}{*}{$\begin{array}{l}\text { o Observación no participante. } \\
\text { o Análisis de documentos } \\
\text { estadísticos, imágenes satelitales, } \\
\text { informes oficiales e informes } \\
\text { científico-académicos. } \\
\text { o Registro de puntos mediante } \\
\text { GPS. } \\
\text { o Entrevistas semiestructuradas. } \\
\text { o Encuestas. } \\
\text { o Conversaciones informales con } \\
\text { vecinos/as. } \\
\text { o Mapeos colectivos. } \\
\text { o Mapeos individuales. }\end{array}$} & \multirow{2}{*}{$\begin{array}{l}\text { o Agentes estatales. } \\
\text { o Vecinos y vecinas. } \\
\text { o Empresas proveedoras del } \\
\text { servicio de transporte público. } \\
\text { o Usuarios de transporte público. }\end{array}$} \\
\hline $\begin{array}{l}\text { Acceso a equipamiento escolar y } \\
\text { sanitario }\end{array}$ & $\begin{array}{l}\text { o Ubicación y cantidad de } \\
\text { establecimientos educativos y } \\
\text { sanitarios. } \\
\text { o Cobertura del servicio de } \\
\text { transporte de pasajeros. } \\
\text { o Ubicación de los conjuntos } \\
\text { barriales. } \\
\text { o Distancias entre los } \\
\text { equipamientos y las viviendas. }\end{array}$ & & \\
\hline $\begin{array}{l}\text { Acceso a las redes de servicios } \\
\text { urbanos de infraestructura }\end{array}$ & $\begin{array}{l}\text { O Distribución de las redes públicas } \\
\text { de servicios urbanos (agua potable, } \\
\text { gas, electricidad, cloacas). } \\
\text { O Viviendas conectadas a la red } \\
\text { pública de cada servicio. }\end{array}$ & & $\begin{array}{l}\text { - Agentes estatales. } \\
\text { o Empresas proveedoras de los } \\
\text { servicios sanitario, gasífero y } \\
\text { eléctrico. } \\
\text { o Vecinos y vecinas. }\end{array}$ \\
\hline
\end{tabular}

de la urbanización mediante la construcción de viviendas de operatoria estatal, con la intención de analizarlo desde la producción de fronteras materiales y simbólicas y, a partir de ahí, elaboramos una propuesta metodológica.

El caso seleccionado presenta en los extremos noreste y noroeste, alejados del centro urbano consolidado y pertenecientes al municipio de Chimbas, una elevada concentración de conjuntos barriales de operatoria estatal. Esta dinámica continúa la tendencia que caracterizó, en décadas previas, la expansión urbana del municipio de Capital, localizado en el borde sur del área de estudio. En este marco, resulta posible advertir que la producción residencial ha colaborado en la configuración de territorios de interfaz urbano-rural, bajo el marco de la expansión urbana sobre territorios rurales.
Entendemos a las fronteras como espacios de contacto que dan cuenta de procesos territoriales que resultan de utilidad para identificar las singularidades de los territorios de interfaz. Por esto, consideramos que constituyen una herramienta valiosa que permite, a partir de la combinación de diversas técnicas de recolección de datos, identificar elementos materiales, así como simbólicos de los procesos evidenciados en los territorios de estudio. No obstante, es importante señalar también los desafíos que implica la propuesta vinculados con la complejidad de las realidades socioespaciales que busca analizar, tales como la multiplicidad de dimensiones intervinientes (económicas, sociales, culturales, políticas, ecológicas, etc.), de agentes involucrados (estatales, comunitarios, privados, científico-académicos, etc.) con diversos intereses y lógicas de actuación y de escalas 
Tabla 2

Identificación de fronteras simbólicas. Reflexiones desde el caso de estudio

\begin{tabular}{|c|c|c|c|}
\hline Fronteras simbólicas & Indicadores y observables & $\begin{array}{l}\text { Técnicas e instrumentos de } \\
\text { recolección de datos }\end{array}$ & $\begin{array}{l}\text { Agentes clave para la recolección } \\
\text { de datos }\end{array}$ \\
\hline $\begin{array}{l}\text { Articulación institucional y } \\
\text { multiactoral }\end{array}$ & $\begin{array}{l}\text { o Disponibilidad de espacios } \\
\text { de participación y trabajo entre } \\
\text { diversos agentes. } \\
\text { o Presencia de regulaciones } \\
\text { territoriales diseñadas de forma } \\
\text { colaborativa. } \\
\text { o Nivel de coordinación de las } \\
\text { áreas estatales vinculadas al OT en } \\
\text { las diversas etapas de las políticas } \\
\text { implementadas. }\end{array}$ & $\begin{array}{l}\text { O Entrevistas semiestructuradas. } \\
\text { ○ Encuestas. } \\
\text { ○ Mapeos colectivos. } \\
\text { ○ Mapeos individuales. } \\
\text { ○ Análisis del discurso. } \\
\text { - Análisis de documentos de } \\
\text { prensa. }\end{array}$ & $\begin{array}{l}\text { o Agentes estatales. } \\
\text { o Vecinos y vecinas. } \\
\text { o Representantes de } \\
\text { organizaciones comunitarias. } \\
\text { o Investigadores/as locales. } \\
\text { o Empresas constructoras y } \\
\text { proveedoras de servicios públicos. }\end{array}$ \\
\hline $\begin{array}{l}\text { Posibilidades de uso y apropiación } \\
\text { de los espacios públicos }\end{array}$ & $\begin{array}{l}\text { o Ubicación de los espacios } \\
\text { públicos. } \\
\text { o Tipología de espacios públicos } \\
\text { existentes. } \\
\text { o Grado de ocupación de los } \\
\text { espacios públicos. } \\
\text { o Tipo y frecuencia de uso dado a } \\
\text { los espacios. } \\
\text { o Expectativas de uso y de } \\
\text { infraestructura disponible. } \\
\text { o Existencia de instancias de } \\
\text { participación comunitaria en el } \\
\text { diseño de los espacios públicos y } \\
\text { en su cuidado o conservación. }\end{array}$ & $\begin{array}{l}\text { o Observación no participante. } \\
\text { ○ Análisis de imágenes satelitales. } \\
\text { o Registro de puntos mediante } \\
\text { GPS. } \\
\text { O Entrevistas semiestructuradas. } \\
\text { o Encuestas. } \\
\text { o Conversaciones informales con } \\
\text { vecinos/as. } \\
\text { o Mapeos colectivos. } \\
\text { o Mapeos individuales. } \\
\text { o Fotografía. }\end{array}$ & \multirow{3}{*}{$\begin{array}{l}\text { o Agentes estatales. } \\
\text { O Vecinos y vecinas. } \\
\text { o Miembros de las organizaciones } \\
\text { comunitarias. } \\
\text { o Investigadores/as locales. }\end{array}$} \\
\hline $\begin{array}{l}\text { Construcción de redes } \\
\text { comunitarias }\end{array}$ & $\begin{array}{l}\text { o Existencia y consolidación de } \\
\text { redes comunitarias. } \\
\text { o Vinculación vecinal dentro y } \\
\text { fuera del barrio. } \\
\text { o Presencia de acciones dirigidas } \\
\text { por vecinos/as. } \\
\text { O Percepciones vecinales sobre } \\
\text { las ideas de lo colectivo y lo } \\
\text { comunitario. } \\
\text { o Participación vecinal en } \\
\text { proyectos locales. }\end{array}$ & \multirow[t]{2}{*}{$\begin{array}{l}\text { o Observación no participante. } \\
\text { o Análisis del discurso. } \\
\text { o Análisis de informes oficiales y } \\
\text { documentos de prensa. } \\
\text { o Entrevistas semiestructuradas. } \\
\text { o Encuestas. } \\
\text { o Conversaciones informales con } \\
\text { vecinos/as. } \\
\text { o Mapeos colectivos. } \\
\text { o Mapeos individuales. }\end{array}$} & \\
\hline $\begin{array}{l}\text { Percepciones sobre barrios } \\
\text { relocalizados }\end{array}$ & $\begin{array}{l}\text { O Imaginarios vecinales en torno a } \\
\text { las ideas de lo propio y lo ajeno. } \\
\text { o Existencia de elementos } \\
\text { diferenciadores de barrios. } \\
\text { o Tipo de relaciones entre } \\
\text { vecinos/as. }\end{array}$ & & \\
\hline
\end{tabular}

analíticas (micro y macro: barrial, municipal, provincial, nacional, internacional).

Por lo expuesto, consideramos que las políticas públicas de carácter territorial, específicamente, las habitacionales y de OT, podrían tender hacia un enfoque integral incorporando la interfaz urbano-rural en la definición de unidades de gestión territorial, a través de la identificación y análisis de las fronteras producidas.

\section{Referencias bibliográficas}

Barsky, A. (2012). La agricultura periurbana en la agenda: complejidad fragmentaria en la gestión pública reciente del cinturón productivo alimentario de la Región Metropolitana de Buenos Aires. Estudios Socioterritoriales, (11), 78-98. http://www.scielo.org.ar/scielo.php?script=sci_ arttext\&pid=S1853-43922012000100004\&lng=es\&t $\underline{\operatorname{lng}=\mathrm{es}}$

Benedetti, A. (2020). Cuatro conceptos de frontera de gran extensión terrestre, claves en la construcción del pensamiento geográfico de la Argentina. TEFROS, (18), 12-46.

Centro de Implementación de Políticas Públicas para la Equidady el Crecimiento, CIPPEC. (2018). La expansión de los Grandes Aglomerados Urbanos argentinos (documento de políticas públicas/recomendación $\mathrm{N}^{\circ}$ 197). Autoedición. https:// www.cippec.org/wp-content/uploads/2018/02/197DPP-Ciudades-La-expansi\%C3\%B3n-de-los-GrandesAglomerados-Urbanos-argentinos-Lanfranchi-DuarteGranero-Enero-2018-1.pdf 
Dalla Torre, J., Sales, R., Esteves, M. y Ghilardi, M. (2019). Los territorios de interfase urbano-rural en tierras secas. Reflexiones sobre su tratamiento en las políticas de ordenamiento territorial de Mendoza. QUID 16, Revista delÁrea de Estudios Urbanos, (11), 137-150. https://publicaciones. sociales.uba.ar/index.php/quid16/article/view/3600/pdf

De Mattos, C. (2002). Transformación de las ciudades latinoamericanas: ¿Impactos de la globalización? EURE, 28(85), 5-10. http://dx.doi.org/10.4067/S025071612002008500001

Di Virgilio, M. M., Guevara, T. y Arqueros Mejica, M. S. (2014). Un análisis comparado sobre la implementación de políticas de regularización de asentamientos informales en Argentina, Brasil y México. Revista INVI, 29(80), 17-51. http://dx.doi.org/10.4067/S0718-83582014000100002

Gobierno de la Nación Argentina y Centro de Investigaciones de Políticas Urbanas y de Vivienda (2017). Ciudades 2030: diagnóstico sobre ciudades y desarrollo urbano. https://www.argentina.gob.ar/sites/default/files/ doc_diagnostico_ciudades_2030_1.pdf

González Maraschio, F. (2018). Factores económicos y extraeconómicos de la renta de la tierra en la interfase rural-urbana del Gran Buenos Aires (1994-2014). Eutopía. Revista De Desarrollo Económico Territorial, (14), 111132. http://dx.doi.org/10.17141/eutopia.14.2018.3602

Gudiño, M. E. (2010). Del urbanismo reglamentario a las nuevas concepciones de ordenamiento territorial. Scripta Nova. Revista Electrónica de Geografía y Ciencias Sociales, 14. http://www.ub.edu/geocrit/sn/sn-331/sn-331-25.htm

Haesbaert, R. (2013). Del mito de la desterritorialización a la multiterritorialidad. Cultura y Representaciones Sociales, 8(15), 9-42. http://www.scielo.org.mx/scielo. php?script=sci_arttext\&pid=S2007-81102013000200001

Instituto Geográfico Nacional de la República Argentina (2020). Catálogo de Objetos Geográficos del Organismo. Base de Datos Geoespacial Institucional. https://www.ign.gob.ar/ NuestrasActividades/InformacionGeoespacial/CapasSIG
Instituto Nacional de Estadística y Censos, INDEC (2010). Censo Nacional de Población, Hogares y Viviendas 2010 de la República Argentina. https://www.indec.gob.ar/

Instituto Nacional de Tecnología Agropecuaria (2020). Determinación de los oasis de regadío de la provincia de San Juan. https://inta.gob.ar/sites/default/files/ intaoasis_de_regadio_san_juan.pdf

Instituto Provincial de la Vivienda (6 de octubre de 2020). Documentación conforme a obra. Departamento de Planificación de IPV, Gobierno de San Juan.

Janoschka, M. (2002). El nuevo modelo de la ciudad latinoamericana: fragmentación y privatización. EURE, 28(85), 11-29. https://doi.org/10.4067/s025071612002008500002

Jirón, P. y Mansilla, P. (2014). Las consecuencias del urbanismo fragmentador en la vida cotidiana de habitantes de la ciudad de Santiago de Chile. EURE, 40(21), 5-28. http:// dx.doi.org/10.4067/S0250-71612014000300001

Ley Provincial N 7491/2004, de 17 dejunio, para implementación del Plan Habitacional "Plan Provincial Vivienda Digna Techo Seguro". Boletín Oficial de la Provincia de San Juan, de 30 de junio de 2004. https://diputadossanjuan.gob. ar/leyes-sancionadas/item/2148-ley-n-7491

Malmod, A. (2011). Lógicas de ocupación en la conformación del territorio. Ordenamiento territorial como instrumento de la planificación. riURB. Revista Iberoamericana de Urbanismo, (6), 19-30. https://upcommons.upc.edu/ bitstream/handle/2099/12520/06Dossier_02_Malmod.pdf

Massiris Cabeza, Á. (2002). Ordenación del territorio en América Latina. Scripta Nova: Revista Electrónica de Geografía y Ciencias Sociales, 6(125), 105-132. http:// www.ub.edu/geocrit/sn/sn-125.htm

Ministerio de Obras Públicas de la Nación Argentina (2011). Programa Argentina Urbana 2011. https://www.argentina. gob.ar/habitat/secretaria-desarrollo-territorial/dnpet/ argentina-urbana 
Ministerio de Planificación e Infraestructura de San Juan, MPI-SJ (2015). Plan de ordenamiento territorial del Área Metropolitana de San Juan (1a ed. revisada). GHM Editores.

Raffestin, C., \& Butler, S. A. (2012). Space, Territory, and Territoriality. Environment and Planning D: Society and Space, 30(1), 121-141. https://doi.org/10.1068/d21311

Rodríguez, N., Vieyra, A., Méndez-Lemus, Y., Hidalgo Dattwyler, R., Alvarado Peterson, V. y Rodríguez, J. (2020). Trayectorias de la periurbanización en Morelia, México: segregación espacial desde un enfoque relacional. Revista de Urbanismo, (42), 88-104.https://doi.org/10.5354/07175051.2020.54924

Rodulfo, M. B. y Boselli, T. (2014). Dilemas y desafíos de la política habitacional argentina desde un enfoque de derechos. Cuadernos de Vivienda y Urbanismo, 7(14), 218-241. https://doi.org/10.11144/Javeriana.CVU714.ddph

Rojas, F., Rubio, M. C., Rizzo, M., Bernabeu, M., Akil, N., \& Martín, F. (2020). Land Use and Land Cover in Irrigated Drylands: a Long-Term. Analysis of Changes in the Mendoza and Tunuyán River Basins, Argentina (1986-2018). Applied Spatial Analysis and Policy, (13), 875-899. https://doi. org/10.1007/s12061-020-09335-6
Rubio, C., Rubio, M.C., \&Abraham, E. (2018). Poverty Assessment in Degraded Rural Drylands in the Monte Desert, Argentina. An Evaluation Using GIS and Multi-criteria Decision Analysis. Social Indicators Research, (137), 579-603 https://doi.org/10.1007/s11205-017-1606-4

Scognamillo, A., Albarracín, O. y Romero, M. (5 de julio, 2016). Hábitat informal e intervenciones públicas: Reflexiones sobre las políticas públicas de erradicación de villas [Sesión de conferencia]. Congreso Internacional Contested Cities "Del conflicto urbano a la construcción de alternativas - diálogos críticos”. Madrid, España.

Taber, E. y Nozica, G. (2011). Problemáticas del crecimiento urbano sobre áreas rurales en sistemas de oasis. riURB Revista Iberoamericana de Urbanismo, (6), 65-71. https://upcommons.upc.edu/bitstream/ handle/2099/12524/06Dossier_06_Nozica_Taber. pdf? sequence $=1 \&$ is Allowed $=\mathrm{y}$

Universidad Nacional de San Juan (2012). Atlas socioeconómico de la provincia de San Juan. http://www.atlas.unsj.edu.ar/ 